\title{
Wave Energy Enhancement for Nearshore Electricity Generation
}

\author{
K.D.R. Jagath Kumara, D.D. Dias, R.L. Nawagamuwa and \\ W.M.A.R. Weerasinghe
}

\begin{abstract}
Sea waves carry $10^{3}-10^{4}$ gigawatts (GWs) of power. Although there are a large number of different approaches to harness offshore wave energy they could be expensive, practically challenging and vulnerable to storms. Therefore, this paper explains how nearshore waves could be used and converged to increase the energy density and generate electricity using a smaller wave energy converter (WEC) than would otherwise be necessary. To illustrate the effectiveness of this approach, some tests were carried out with a physical model of a manipulator both in steady, uniform waves and in random waves created in a wave flume representing different sea states. The results include comparisons between theoretical predictions and wave flume tests with respect to incident wave energy, loss in manipulation and increase in energy density for different settings of the manipulator. The paper also presents the brake torque and angular velocity of two single duct, axial flow turbines placed in manipulated waves. It is found that wave manipulation creates energetic off shore waves close to nearshore which makes it suitable for typical offshore WECs. The paper also discusses morphodynamics and ecological issues and outlines the advantages of building coastal structures for wave manipulation.
\end{abstract}

Keywords: Nearshore waves, Wave energy conversion, Wave manipulation, Nearshore morphodynamics and ecology.

\section{Introduction}

The utilization of ocean waves for energy generation first started in France, the United States, and the UK in the 1800's. According to literature [1], [2] the energy available in sea waves is very high. In some offshore locations in both hemispheres, the monthly average of the available wave power is as high as 200 $\mathrm{kW} / \mathrm{m}[2]$. However, the annual averages in the coastal areas vary in the range $5-50 \mathrm{~kW} / \mathrm{m} \mathrm{[3].}$

The southern and western coastal regions of Sri Lanka receive $30-40 \mathrm{~kW} / \mathrm{m}$ waves in the month of July [3]. The lowest monthly averages in these regions is $10-15 \mathrm{~kW} / \mathrm{m}$ which is in January. The annual averages in the same regions in Sri Lanka are $20-30 \mathrm{~kW} / \mathrm{m}$ while it is $5-10 \mathrm{~kW} / \mathrm{m}$ in the eastern shore [4]. According to the surf forecast made for Galle using a buoy located $24 \mathrm{~km}$ away from the shore [5], waves of $2-3 \mathrm{~m}$ height occur during $80 \%$ of the time in June and July. Note that these wave fronts suffer no significant loss until they reach the surfzone where they start breaking. The wave energy gradually dissipates afterwards while the waves continue to break and propagate towards the shore line. The surf forecast also suggests that the nearshore statistics would be somewhat less. However, the percentage of waves 2-3 $\mathrm{m}$ in height reduces to about $40 \%$ in the months of May, August and September.
During $80 \%$ of the time of the period from December to March, the wave heights range only from $0.5-1.3 \mathrm{~m}$. The energy forecast made for Galle on the $11^{\text {th }}$ of June 2015 was for a 957 $\mathrm{KJ} / \mathrm{m} /$ wave with a period of $16 \mathrm{~s}$ and a height of $1.4 \mathrm{~m}$, suggesting that about $60 \mathrm{~kW} / \mathrm{m}$ of power would be available [5]. The energy forecasts for other months also resemble the power availabilities mentioned in [3] and [4].

As the sea waves are freely available throughout day and night, the power plants using sea wave energy should be inexpensive requiring only the cost of installation and maintenance. They are also environmentally

Eng. (Dr.) K.D.R. Jagath Kumara, C. Eng., MIE(SL),

B.Sc. Eng. (Hons) (Peradeniya), M.Eng.Sc. (UNSW), Ph.D.

(UniSA), Senior Lecturer, Department of Electrical \&

Electronic Engineering, University of Peradeniya.

Email:jagathk@ee.pdn.ac.lk

Mr. D.D. Dias, B.Sc. Eng. (Hons) (Peradeniya),

M.Eng.(Hokkaido), Lecturer, Department of Civil

Engineering, University of Peradeniya.

Email:daham@pdn.ac.lk

Eng. R.L. Nawagamuwa, AMIE(SL), B.Sc. Eng. (Hons) (Peradeniya), Civil Site Engineer, Sierra Construction (Pvt) ltd., Sri Lanka.

Email:featraj@gmail.com

Eng. W.M.A.R. Weerasinghe, AMIE(SL), B.Sc. Eng.

(Hons) (Peradeniya), Civil Engineer, Mahaweli Authority, Sri Lanka.

Email:ayesharw06@gmail.com 
friendly as they cause no pollution. However, most of the currently available sea wave power plants are located offshore and thus require substantial engineering efforts for their installation and maintenance. Therefore, it is appropriate to consider alternative approaches which are relatively less expensive and more reliable. This paper investigates the potential of utilizing nearshore waves for generating electricity to overcome the fundamental problems associated with sea wave energy conversion. Initial research carried out by the authors on this subject are described in [6] and [7].

In this case, firstly, the nearshore wave fronts are funneled into a channel to increase wave energy density. The main advantage of this manipulation is that it enables to capture the energy of waves at the funnel entrance with a higher crest length, by using a turbine with a smaller diameter inside the channel. Secondly, after harnessing the energy of the waves inside the channel, the waves are dispersed using a suitable diffuser to reduce coastal erosion. Nearshore wave power plants would be less vulnerable to offshore hazards, although the energy available from them would be lower. This paper essentially describes the testing of a model wave manipulator and the experimental results obtained using an axial flow, horizontal axis turbine.

Section 2 of this paper outlines important information pertaining to wave energy harnessing around the world and the main problems associated with wave energy conversion. Section 3 explains the concept of wave energy enhancement, quantifies some major design parameters and describes the tests to be carried out on a wave manipulator model. Section 4 describes the testing environment of the laboratory. Thereafter, it illustrates some of the wave parameters that were measured and how the energy density increases under different wave conditions enabling comparisons with theoretical predictions. Section 5 presents the test results obtained by mounting an existing type of a turbine inside the model manipulator. It further estimates the amounts of extracted energy and power, and the corresponding conversion efficiencies for the turbine. Section 6 discusses morphodynamic and ecological issues. Section 7 highlights some of the additional advantages of coastal structures built for wave manipulation.

\section{Wave Energy Harnessing- Key Implementations and Issues}

There is no doubt that the energy available with sea waves of certain locations is adequate for use in a power plant of a useful scale. However, the fundamental problem is to harness this energy efficiently. Many different approaches have been used so far for generating electricity by using not only the surface waves but also the tidal waves of the sea [4], [6]-[12], [15]-[19]. For example, a low head hydro turbine fed by a $3 \mathrm{~m}$ high overtopping reservoir in an island off Bergen, Norway had an installed capacity of $350 \mathrm{~kW}$ [8]. This power station was expected to produce 2 GWh annually using $10-15 \mathrm{~kW} / \mathrm{m}$ waves which were guided up to the reservoir along a $90 \mathrm{~m}$ tapered channel (Tap Chan). A $19.6 \mathrm{~m}$ diameter oscillating water column (OWC) device, installed at a depth of $7 \mathrm{~m}$ in water in the same location generated 100- 500 $\mathrm{kW}$ using a Wells turbine [8]. A 1 MW demonstrative installation of another OWC was $21 \mathrm{~m}$ wide and $24 \mathrm{~m}$ long [9]. A point absorber type WEC in Portugal provided 751MWh annually. The effective dimensions of this device, generating an annual average power of $86 \mathrm{~kW}$ when the annual available surface wave power was $38 \mathrm{~kW} / \mathrm{m}$, were in the order of 4-6.5 $\mathrm{m}$ [4], [10]. The point absorber type WEC described in [11] has a rated capacity of $250 \mathrm{~kW}$. A $10 \mathrm{MW}$ power station would require 40 of them installed in an area of 16 acres in $30-50$ $\mathrm{m}$ deep water, about 1.6 to $8 \mathrm{~km}$ offshore. A 140 $\mathrm{m}$ long, $3.5 \mathrm{~m}$ in diameter, four segment device with three joints, which is known as Pelamis, has a total power rating of $750 \mathrm{~kW}$ [11]. Such a WEC is typically installed about $3-24 \mathrm{~km}$ offshore in water 50-70 m deep. A $30 \mathrm{MW}$ power station would span 250 acres of sea area. In tidal flow, a wide bladed turbine having a diameter of $2.44 \mathrm{~m}$ had a total capacity of $45 \mathrm{~kW}$ at a flow velocity of $2.5 \mathrm{~m} / \mathrm{s}$, resulting in an overall efficiency of $57.1 \%$ [12].

The current cost of electricity generated using these approaches ranges from $0.07-0.10 \$ / \mathrm{kWh}$. For example, a study carried out in Australia [13] suggests a cost of $100 \$ / \mathrm{MWh}$ or 0.10 $\$ / \mathrm{kWh}$ for sea wave energy. A case study done in Tenerife, Spain discusses the effects of a wave farm on the nearshore wave climate [14].

The seasonal fluctuation of wave statistics is an important parameter, which determines the implementation complexity of a wave energy conversion system [3], [4]. If the ratio between the highest and the mean wave heights at a particular location is high, the design cost of the 
wave energy power plant would be high because it would be necessary to consider a large range of values for a given design parameter such as the size of the turbine, strength of the supporting structures, and the ratings of the electrical system. For example, this ratio is about 10 for the Northern Hemisphere suggesting large seasonal fluctuations. However, in the Sri Lankan coasts, it is about only three [3], [4]. Additionally, the minimum monthly average of the available power with respect to the annual average is about $60-70 \%$ showing that the fluctuations in Sri Lanka are much smaller. Therefore, the design complexity and the construction cost of a wave power plant would be lower in Sri Lanka compared to the Northern Hemisphere. This is also true for those countries near the equator and the Southern Hemisphere.

\section{Nearshore Energy Harnessing using Wave Concentration}

The energy and the power of a wave are proportional to its crest width $(w)$. Therefore, any electro-mechanical system which converts nearshore wave energy must have the dimensions in the order of hundreds of meters in order to generate a few MWs of power, setting a major practical limit. As a solution, this paper considers manipulating the waves, concentrating them into a channel where their energy density becomes much higher than that of the original incident waves. It has to be noted that as described in below this concept is structurally and functionally different from the Tap Chan [8].

Figure 1 illustrates the schematic diagram of a nearshore structure which would funnel, stabilize and diffuse waves [6]-[7]. The funnel section converges very wide waves $\left(w_{1}\right)$ into narrow waves $\left(w_{2}\right)$, where $w_{1}>w_{2}$. The channel allows these narrow waves to stabilize, for example, with respect to the direction of the movement, wave length and the height. In addition, the wave length increases inside the channel enhancing the energy density. The increase in wave height too contributes to this increase in energy density although this increase is insignificant compared to the increase caused by the wavelength. Once, an appropriate electro-mechanical assembly converts this energy, the diffuser will inverse the funneling function. This will effectively and considerably control coastal erosion and flooding. In Figure $1, l_{1}, l_{2}$, and $l_{3}$ are the lengths of the corresponding sections, $\alpha$ and $\beta$ are the funneling and diffusing angles, and $w_{3}$ is the width of the diffuser exit.

The theoretical research presented in [20] and [21] too suggest that the wavelength and height change with the width of the channel, which confirms the effectiveness of the approach. For example, [20] solves the Laplace equation with appropriate boundary conditions for a three dimensional domain and illustrates a set of curves showing the variation of the wave number with $2 m \pi / w$ for a given wave frequency where $w$ is the channel width (crest width) and $m$ is an integer. It is possible to deduce from these curves that the wavelength $(\lambda)$ is piecewise linear with respect to $1 / w$ for a certain range of $w$. In addition, $\lambda$ is approximately and directly proportional to $1 / w$ when $w$ is neither too small nor too large.

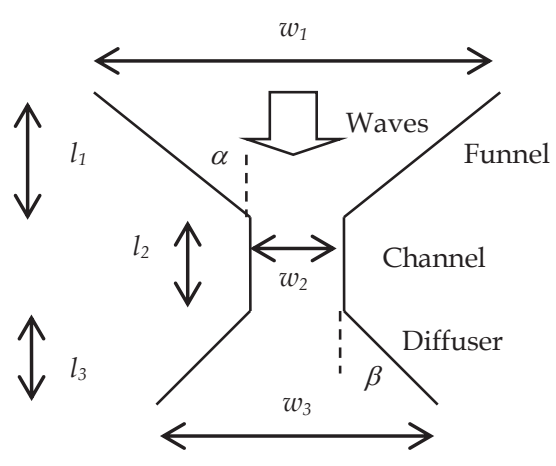

Figure 1 - Funneling, channeling and
dispersion

It can be shown both experimentally and numerically [21] that $\lambda$ varies in the converging and diverging channels. In addition, in a converging channel the amplitudes of the waves should increase in proportion to $w^{-0.5}$ and in a diverging channel they should decrease in proportion to $w^{-0.66}$. The two theoretical studies [20], [21] provide qualitative justifications while [20] provides quantitative justifications for the analysis given below.

The effectiveness of the wave manipulation process could be quantified using the ratio of the amount of energy per meter of width of the incident wave to that of the wave inside the channel. According to linear wave theory, for steady and uniform sinusoidal waves, the total energy over a wavelength $(E)$ is given by the following equation [22]:

$$
E=0.5 \rho g \lambda w a^{2} ; a<<\lambda
$$

where $\rho, g$ and $a$ are the density of water, gravitational acceleration and the wave 
amplitude respectively. Note that (1) includes equal amounts of kinetic and potential energy. Then, the energy per unit width $(e)$ could be calculated as given below.

$$
e=\frac{E}{w}=0.5 \rho g \lambda a^{2} .
$$

Therefore, the coefficient of energy density increase would be as follows:

$$
c_{\text {edi }}^{\mathrm{sin}}=\frac{e_{2}}{e_{1}}=\frac{0.5 \rho g \lambda_{2} a_{2}^{2}}{0.5 \rho g \lambda_{1} a_{1}^{2}}
$$

where suffixes 1 and 2 represent the corresponding parameters of the incident wave and the wave inside the channel respectively. Since it is assumed that in linear waves the wave amplitude is very small, $a_{1}$ will be approximately equal to $a_{2}$. In addition, the percentage increase in the amplitude due to manipulation will be much smaller than the increase in the wavelength. Hence, from (3),

$$
c_{e d i}^{\text {sin }} \approx \frac{\lambda_{2}}{\lambda_{1}} .
$$

As described in the preceding section and as indicated below, the wavelength will be inversely and approximately proportional to the width of the wave.

$$
\lambda \propto \frac{1}{w} .
$$

Hence,

$$
\frac{\lambda_{2}}{\lambda_{1}} \approx \frac{w_{1}}{w_{2}} .
$$

By combining (4) and (6),

$$
c_{e d i}^{\sin } \approx \frac{w_{1}}{w_{2}}
$$

where $w_{1} / w_{2}$ is the funneling ratio. According to (4) and (7), the effectiveness of the process corresponds directly to the increase in the wavelength or the funneling ratio. However, these predictions will be valid only for a certain range of widths.

It has to be noted that there are losses $(L)$ in the wave manipulation process caused by reflections, eddies and other processes. It will be shown in the results section that $L$ is small for reasonable values of the funneling ratios. Hence (4) and (7) are good indicators of the effectiveness of the wave manipulation process.

\subsection{A Model of a Wave Manipulator}

To test the applicability and the predicted effectiveness of wave manipulation, it is first necessary to build a model manipulator. This should also help estimating the optimal dimensions and the power generation capacity of a real prototype for given wave conditions.

For example, if $w_{1} / w_{2}$ is too high, the increase in the energy density will be smaller than what is expected due to increased losses. Particularly, if $w_{2}$ is very small, a stagnation point will occur close to channel entrance and the volumetric flow through the channel may also become very small. By plotting the energy loss due to manipulation $(L)$ while keeping $w_{1}$ constant and decreasing $w_{2}$ from $w_{1}$ to a smaller value, the optimum value of $w_{2}\left(w_{2, \text { opt }}\right)$ could be found [7]. In this plot, the point at which $L$ begins to rise sharply corresponds to $w_{2, o p t}$.

The manipulator model was constructed using aluminum to minimize frictional losses and to enhance the durability. The length of the channel $\left(b_{2}\right)$ was $2 \mathrm{~m}$. The channel width $\left(w_{2}\right)$ could be adjusted by sliding the walls of the channel. The funnel and the diffuser, each $0.5 \mathrm{~m}$ long, were joined to the channel by using hinges so that $w_{1}$ and $w_{3}$ as well as $b_{1}$ and $b_{3}$ could be changed. All the three sections had a constant height of $1.2 \mathrm{~m}$.

\section{Tests Carried Out in Steady Waves and in Random Waves}

The model was partially submerged in a large wave flume at the Fluid Mechanics Laboratory, University of Peradeniya. This flume was $30 \mathrm{~m}$ long, $1.8 \mathrm{~m}$ wide and $2.1 \mathrm{~m}$ deep, and consisted of smooth concrete walls as illustrated in Figure 2. The level of the still water was kept at $1.2 \mathrm{~m}$. A plunger type wave maker with different settings, $D i, \quad i=0$ to 7 , fitted with the flume, could generate different waves.

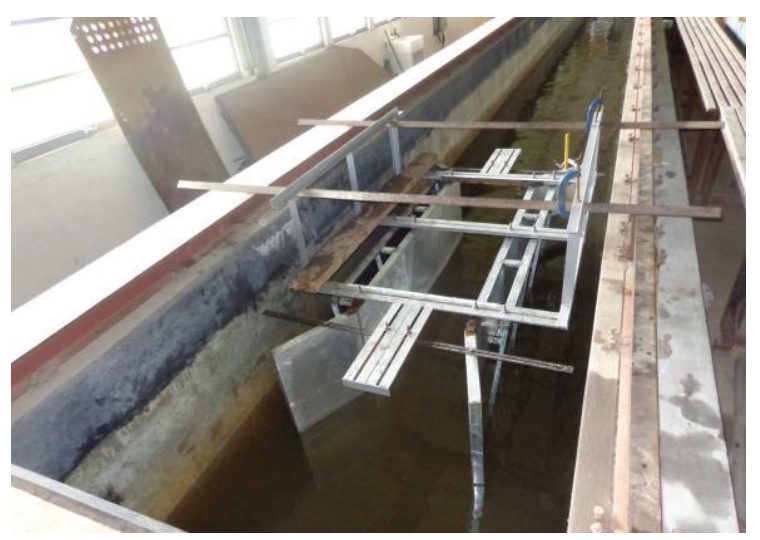

Figure 2 - Photograph of the model manipulator in the flume 


\subsection{Steady Sinusoidal Waves}

A steady, uniform sinusoidal incident wave having a wavelength, $\lambda_{1}$, of $1.3 \mathrm{~m}$ and a height, $H_{1}\left(=2 a_{1}\right)$, of $0.34 \mathrm{~m}$, could be generated with the setting of D0 on the control panel of the wave maker. First, the wave parameters in the channel section $\left(\lambda_{2}, H_{2}\right)$ were measured for $w_{1}=$ $0.67 \mathrm{~m}$ and $0.957 \mathrm{~m}$ by keeping $w_{2}=0.25 \mathrm{~m}$. Thereafter, the same wave parameters were measured for $w_{1}=0.86 \mathrm{~m}$ and $w_{2}=0.45 \mathrm{~m}$. One set of measurements for each setting of the manipulator was sufficient as the waves were steady. These, together with the corresponding values of $\lambda_{2 /} \lambda_{1}$, are listed in Tables 1 and 2 .

Table 1 - Parameters measured for $w_{2}=0.25 \mathrm{~m}$

\begin{tabular}{|c|c|c|c|}
\hline$w_{1}(\mathrm{~m})$ & $H_{2}(\mathrm{~m})$ & $\lambda_{2}(\mathrm{~m})$ & $\lambda_{2} / \lambda_{1}$ \\
\hline 0.670 & 0.38 & 2.7 & 2.1 \\
\hline 0.957 & 0.45 & 2.6 & 2.0 \\
\hline
\end{tabular}

Table 2 - Parameters measured for $w_{2}=0.45 \mathrm{~m}$

\begin{tabular}{|c|c|c|c|}
\hline$w_{1}(\mathrm{~m})$ & $H_{2}(\mathrm{~m})$ & $\lambda_{2}(\mathrm{~m})$ & $\lambda_{2} / \lambda_{1}$ \\
\hline 0.860 & 0.39 & 1.8 & 1.4 \\
\hline
\end{tabular}

Table 3 - Energy Densities for $w_{2}=0.25 \mathrm{~m}$

\begin{tabular}{|c|c|c|c|c|c|c|}
\hline $\begin{array}{c}w_{1} / \\
w_{2}\end{array}$ & $\begin{array}{c}E_{1} \\
(\mathrm{~J})\end{array}$ & $\begin{array}{c}E_{2} \\
(\mathrm{~J})\end{array}$ & $\begin{array}{c}L \\
(\mathrm{~J})\end{array}$ & $\begin{array}{c}e_{1} \\
(\mathrm{~J} / \mathrm{m})\end{array}$ & $\begin{array}{c}e_{2} \\
(\mathrm{~J} / \mathrm{m})\end{array}$ & $C_{\text {edi }}^{\text {sin }}$ \\
\hline 2.7 & 123 & 119 & 4 & 184 & 478 & 2.6 \\
\hline 3.8 & 176 & 161 & 15 & 184 & 645 & 3.5 \\
\hline
\end{tabular}

Table 4 - Energy Densities for $w_{2}=0.45 \mathrm{~m}$

\begin{tabular}{|c|c|c|c|c|c|c|}
\hline $\begin{array}{c}w_{1} / \\
w_{2}\end{array}$ & $\begin{array}{c}E_{1} \\
(\mathrm{~J})\end{array}$ & $\begin{array}{c}E_{2} \\
(\mathrm{~J})\end{array}$ & $\begin{array}{c}L \\
(\mathrm{~J})\end{array}$ & $\begin{array}{c}e_{1} \\
(\mathrm{~J} / \mathrm{m})\end{array}$ & $\begin{array}{c}e_{2} \\
(\mathrm{~J} / \mathrm{m})\end{array}$ & $C_{\text {edi }}^{\text {sin }}$ \\
\hline 1.9 & 158 & 151 & 7 & 184 & 335 & 1.8 \\
\hline
\end{tabular}

The total energy of the incident wave captured by the funnel $\left(E_{1}\right)$ and that of the wave in the channel $\left(E_{2}\right)$ were calculated from (1) using the data given in Tables 1 and 2. Tables 3 and 4 include those energies $\left(E_{1}\right.$ and $\left.E_{2}\right)$ and the energy losses $\left(L=E_{1}-E_{2}\right)$ that occur during manipulation. These tables also include the energy densities $\left(e_{1}\right.$ and $\left.e_{2}\right)$ and the corresponding $C_{\text {edi }}^{\text {sin }}$ found using (2) and (3) respectively. As described by the authors in [6] and [7], for steady and uniform waves, estimations based on the laboratory test results confirm that $c_{\text {eli }}^{\text {sin }}$ is very close to $w_{1} / w_{2}$ for the selected values of $w_{1}$ and $w_{2}$. Furthermore, the percentage loss that occurs during the energy manipulation process is less than $10 \%$.

The wave length ratios $\left(\lambda_{2} / \lambda_{1}\right)$ are not very different from the corresponding $c_{e t i}^{\text {sin }}$ as predicted by (4), except for the second set of readings given in Tables 1 and 3. In this case, the proportional increase in $H$ is higher than that in $\lambda$ and thus the enhancement of energy density is mostly due to $H$, making (4) to be invalid. The possible reason for this behavior is that $w_{1}(=0.96 \mathrm{~m})$ in this case is outside the linear region established in Section 3.

It was observed that once the waves entered the diffuser, the wave heights dropped resulting in a rapid flow of water. This flow continued for a distance of about $1.5 \mathrm{~m}$ past the exit of the diffuser where the waves got transformed into the original sinusoidal form. This confirmed that the diffuser could effectively diffuse the manipulated waves.

\subsection{Random Waves}

By adjusting the wave breaker at the far end of the flume, it was possible to vary the parameters of the incident wave from time to time for a given setting of the wave maker. In this case, it was practically difficult to measure the same wave crest before manipulation (incident wave) and after manipulation (wave in the channel). However, a set of repeated measurements taken over a certain time period indicated that the incident wave parameters varied more or less randomly. Therefore, for a fixed setting of the wave maker, the set of possible waves would represent a stationary 'sea state'. The assumption of stationary condition is also due to the constant power supplied by the wave maker at a given setting. The wave parameters in the channel were also found to vary randomly.

For the purpose of validating the effectiveness of wave manipulation in random waves, a set of measurements of the incident waves were first taken for the setting D0 of the wave maker. Then, another set of measurements were taken in the channel section for the same wave maker setting. The procedure was repeated for a total of four settings, D0, D1, D2 and D3. With these tests, the funnel entrance $\left(w_{1}\right)$ and the channel width $\left(w_{2}\right)$ were kept constant at $0.95 \mathrm{~m}$ and $0.45 \mathrm{~m}$ respectively. These measured data were analyzed in different ways: simple averaging of the wave parameters and estimating mean significant wave heights.

\subsubsection{Simple Averaging for the Setting D0}

In this case, each individual measurement of the wavelength, $\lambda_{i, n}$, and the height, $H_{i, n}$, were considered to represent an individual sinusoidal wave where the incident wave and the wave in the channel section are identified by the suffix $i=1$ or 2 respectively. Each individual item of a set of measurements is $n\left(n=1,2, \ldots N_{i}\right)$ and $N_{i}$ is the total number of 
measurements taken. Therefore, the averages of the wavelengths and heights were found by

$$
\lambda_{i, \text { ave }}=\frac{\sum_{n=1}^{N_{i}} \lambda_{i, n}}{N_{i}} ; \quad H_{i, \text { ave }}=\frac{\sum_{n=1}^{N_{i}} H_{i, n}}{N_{i}}
$$

Table 5 lists these averages and Table 6 lists the total energies, manipulation losses, energy densities and the coefficient of energy density increases estimated using (1) - (3).

Table 5 - Averaged wave parameters for $w_{1}=0.95 \mathrm{~m}, w_{2}=0.45 \mathrm{~m}$

\begin{tabular}{|c|c|c|c|}
\hline$\lambda_{1, \text { ave }}(\mathrm{m})$ & $H_{1, \text { ave }}(\mathrm{m})$ & $\lambda_{2, \text { ave }}(\mathrm{m})$ & $H_{2, \text { ave }}(\mathrm{m})$ \\
\hline 1.661 & 0.306 & 2.205 & 0.362 \\
\hline
\end{tabular}

Table 6 - Energy densities obtained using averages

\begin{tabular}{|c|c|c|c|c|c|c|}
\hline $\begin{array}{c}w_{1} / \\
w_{2}\end{array}$ & $\begin{array}{c}E_{1} \\
(\mathrm{~J})\end{array}$ & $\begin{array}{c}E_{2} \\
(\mathrm{~J})\end{array}$ & $\begin{array}{c}L \\
(\mathrm{~J})\end{array}$ & $\begin{array}{c}e_{1} \\
(\mathrm{~J} / \mathrm{m})\end{array}$ & $\begin{array}{c}e_{2} \\
(\mathrm{~J} / \mathrm{m})\end{array}$ & $C_{\text {edi }}^{\text {sin }}$ \\
\hline 2.1 & 181 & 159 & 22 & 191 & 353 & 1.9 \\
\hline
\end{tabular}

The results given in Table 6 confirm that the wave manipulation causes a loss of about $10 \%$ and that $C_{\text {edi }}^{\text {sin }}$ is close to $w_{1} / w_{2}$ as predicted by (7) even when wave parameters vary randomly.

\subsubsection{Using Mean Significant Heights for the Setting D0}

According to linear wave theory, the average wave energy density $\left(e_{\text {ave }}\right)$ in a stationary sea state is expressed in terms of the mean significant height $(\mathrm{Hs})$ of the waves as indicated below.

$$
e_{\text {ave }}=\frac{1}{8} \rho g H_{s}^{2}
$$

In (9), Hs is the average of the highest one third of the set of waves observed over a reasonable period of time [22], [23]. This definition of Hs has been commonly used in the literature and is often adequate for practical purposes [1]. Here, the unit of $e_{\text {ave }}$ is $\mathrm{J} / \mathrm{m}^{2}$ of the surface area of the wave environment.

With this wave setting of D0, the averages were found to be fairly constant over a measurement period of about one hour and hence the corresponding set of wave parameters were considered to define a unique sea state. If the averages of the wave parameters are different after a certain period of time, the sea state will be different. In this case, the mean significant height of the incident waves and that of the waves in the channel section were found using the following equation:

$$
H s_{i}=\left(\sum_{n=1}^{N_{i} / 3}\left\{H_{i, n}\right\}\right) /\left(N_{i} / 3\right)
$$

In (10), $\left\{H_{i, n}\right\}$ is the list of wave heights in the descending order. Table 7 lists the mean significant wave heights $\left(H s_{1}\right.$ and $\left.H s_{2}\right)$, average energy densities ( $e_{1, \text { ave }}$ and $\left.e_{2, a v e}\right)$ and the coefficient of energy density increases $\left(\frac{e_{2, \text { ave }}}{e_{1, \text { ave }}}\right)$, now termed $c_{\text {edi }}^{\text {state } 0}$ for the sea state D0. It is observed that the energy density gets enhanced in the channel.

Table 7 - Energy densities using the mean significant heights for the sea state D0

\begin{tabular}{|c|c|c|c|c|c|}
\hline $\begin{array}{c}w_{1} / \\
w_{2}\end{array}$ & $\begin{array}{c}H s_{1} \\
(\mathrm{~m})\end{array}$ & $\begin{array}{c}H s_{2} \\
(\mathrm{~m})\end{array}$ & $\begin{array}{c}e_{1, \text { ave }} \\
\left(\mathrm{J} / \mathrm{m}^{2}\right)\end{array}$ & $\begin{array}{c}e_{2, \text { ave }} \\
\left(\mathrm{J} / \mathrm{m}^{2}\right)\end{array}$ & $C_{\text {etit }}^{\text {state } 0}$ \\
\hline 2.1 & 0.337 & 0.47 & 142 & 276 & 1.9 \\
\hline
\end{tabular}

The energy densities given in Table 7 are rather different from those given in the previous sections because (9) expresses them per $\mathrm{m}^{2}$ of the surface area of the 'wave sea' whereas (2) expresses them per wavelength and per meter of crest length.

\subsubsection{Using the Measurements of all the Settings}

The averages and the variances of the different sets of wave parameter measurements taken for the settings D0, D1, D2 and D3 increase in the same order. This indicates that they correspond to four different sea states. Therefore, it was assumed that by combining all the sets of measurements, a more realistic random wave sea could be approximated. The difference is that in a real sea, the wave parameters would be drawn from any of the many possible sea states. With these tests, a given sea state (wave setting) selected out of four, was kept steady while the measurements were taken before the sea state was changed to the next state. However, under normal circumstances, the real sea too could produce steady waves at least for some time. Therefore, this approximation would have been very close if the measurements were taken for more wave settings than just four.

The measurements of these four settings were nevertheless combined and sorted to find the mean significant wave height using (10). Since the number of sea states was only four and the 
waves in all the four states were more or less sinusoidal (periodic) with almost constant periods of around $1.2 \mathrm{~s}$, the average energy densities were found using (9). Table 8 lists the mean significant wave heights, average energy densities and the corresponding increases in the coefficient of energy density $\left(c_{\text {edi }}^{4 \text { states }}\right)$ for the combined sea states. The mean significant wave heights and the energy densities are higher because the sea states D1, D2 and D3 are more energetic than D0. In this case too, it is observed that energy density is enhanced in the channel.

Table 8 - Energy densities using mean significant heights for the four sea states

\begin{tabular}{|c|c|c|c|c|c|}
\hline $\begin{array}{c}w_{1} / \\
w_{2}\end{array}$ & $\begin{array}{c}H s_{1} \\
(\mathrm{~m})\end{array}$ & $\begin{array}{c}H s_{2} \\
(\mathrm{~m})\end{array}$ & $\begin{array}{c}e_{1, \text { ave }} \\
\left(\mathrm{J} / \mathrm{m}^{2}\right)\end{array}$ & $\begin{array}{c}e_{2, \text { ave }} \\
\left(\mathrm{J} / \mathrm{m}^{2}\right)\end{array}$ & $c_{\text {edi }}^{4 \text { states }}$ \\
\hline 2.1 & 0.376 & 0.539 & 177 & 363 & 2.1 \\
\hline
\end{tabular}

\section{A Turbine Suitable for Enhanced Nearshore Waves}

When the sea waves are manipulated to increase their kinetic energy densities, the resulting flow is somewhat similar to that of a jet and that of a free flow. It becomes impulsive periodically (corresponding to the original wave crests) with a fluctuating volumetric flow rate. Therefore, both impulse turbines and freeflow turbines [11], [15], [16] could be used in this application. In particular, the Pelton-wheel, the water-wheel, or a combination of the two may be the most suitable type of turbine. Some important features of such a turbine with multiple ducts for guiding the fluctuating wave fronts are described in [7].

\subsection{Testing the Manipulator with a Turbine Model}

According to literature, in free flow channels, axial flow, horizontal axis turbines with wide blades (fan type) have an efficiency which is close to $50 \%$ [11], [12]. Therefore, two fan blade type horizontal axis turbines with diameters of $D_{1}=0.18 \mathrm{~m}$ and $D_{2}=0.38 \mathrm{~m}$ were assembled for this use in this application. First, as illustrated in Figure 3, the smaller one was installed at the end of the channel by keeping $\mathrm{w}_{2}=0.25 \mathrm{~m}$. For an incident wave with $\lambda_{1}=1.3 \mathrm{~m}$ and $h_{1}=0.34 \mathrm{~m}$, brake torque $(\tau)$ and angular velocity $(\omega)$ were measured. These measured values for $w_{1}=$ $0.670 \mathrm{~m}$ and $0.957 \mathrm{~m}$ are listed in Table 9. Then, the procedure was repeated with the $0.38 \mathrm{~m}$ turbine by setting $w_{1}=0.860 \mathrm{~m}$ and $w_{2}=0.45 \mathrm{~m}$. The measured values are given in Table 10. The results in these tables include only those taken for steady sinusoidal waves.
In order to estimate the energy transferred to the turbine, the inertia of the $0.18 \mathrm{~m}$ turbine $(I)$ was measured. In this experiment, one of the turbine blades was fitted with another small mass to make it swing like a pendulum. The period of oscillation ( $T$ ) was found by averaging the time taken for a reasonable number of swings. Then, using $T, I$ was found to be $0.0064 \mathrm{kgm}^{2}$. When the funneling ratio was 2.7 , the angular velocity $(\omega)$ of the turbine was $1205 \mathrm{rpm}$ (Table 9). Therefore, as shown in Table 3 , the average mechanical energy $\left(E_{m}\right)$ of the rotating turbine is $51 \mathrm{~J}$ where $E_{m}=0.51 \omega^{2}$, while the available wave energy in the channel $\left(E_{2}\right)$ for this setting is $119 \mathrm{~J} /$ wave. These figures suggest an energy conversion efficiency of $43 \%$. The $0.18 \mathrm{~m}$ turbine could capture only $27 \%$ of the $0.38 \mathrm{~m}$ high wave peaks (Table 1 ) in the 0.25 $m$ wide channel $\left[\pi \times\left(0.09^{2}\right) / 0.38 \times 0.25\right]$. The efficiency would be much higher, if the percentage wave capture area of the turbine was higher.

For the same setting, the power captured by the turbine could be $40 \mathrm{~W}$ as given by $(0.5 \times$ braketorque $) \times(0.5 \times$ noloadangularvelocity $)$ which is $0.5 \times 1.3 \times 0.5 \times 1205 \times 2 \pi / 60$ assuming that the torque speed characteristic is linear and that the self-load of the turbine is negligible. In this case, the available power in the channel is $99 \mathrm{~W}$ [119 J/period (1.2 s)] suggesting a power conversion efficiency of $40 \%$ (40/99). The low efficiency is again due to the low wave capture area of $27 \%$.

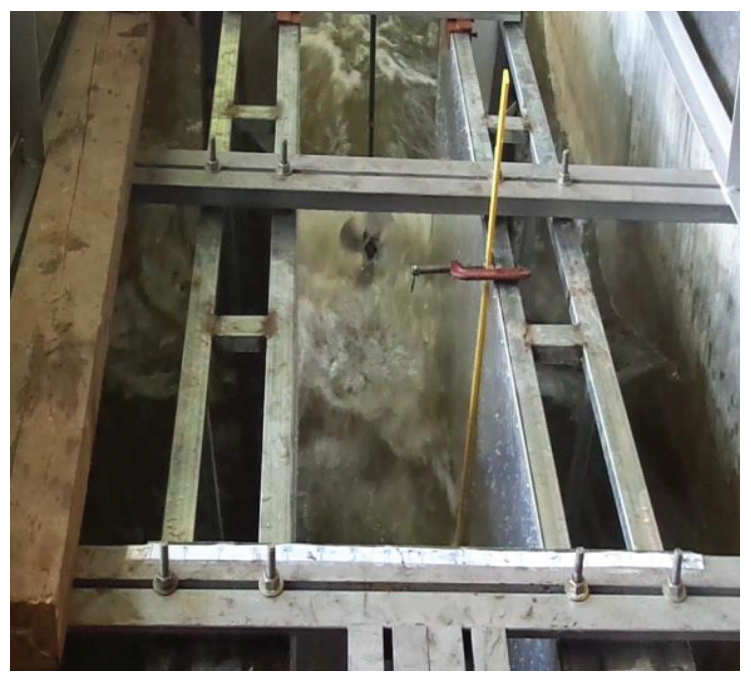

Figure 3 - Turbine placed at the channel end

The $0.38 \mathrm{~m}$ turbine could capture most of the energy of the $0.39 \mathrm{~m}$ high waves (Table 2) in the channel. In this case, the wave capture area of $65 \%\left[\pi\left(0.19^{2}\right) / 0.39 \times 0.45\right]$, contributed to the 
increase in the brake torque by a factor of about $12(15.6 / 1.3)$.

Table 9 - Turbine measurements $\left(D_{1}=0.18 \mathrm{~m}\right.$, $\left.w_{2}=0.25 \mathrm{~m}\right)$

\begin{tabular}{|c|c|c|c|}
\hline$w_{1}(\mathrm{~m})$ & $w_{1} / w_{2}$ & $\tau(\mathrm{Nm})$ & $\omega(\mathrm{rpm})$ \\
\hline 0.670 & 2.7 & 1.3 & 1205 \\
\hline 0.957 & 3.8 & 1.5 & 833 \\
\hline
\end{tabular}

Table 10 - Turbine measurements $\left(D_{2}=0.38 \mathrm{~m}\right.$, $w_{2}=0.45 \mathrm{~m}$ )

\begin{tabular}{|c|c|c|c|}
\hline$w_{1}(\mathrm{~m})$ & $w_{1} / w_{2}$ & $\tau(\mathrm{Nm})$ & $\omega(\mathrm{rpm})$ \\
\hline 0.860 & 1.9 & 15.6 & - \\
\hline
\end{tabular}

\section{Morphodynamic and Ecological Issues}

Ideally, the wave manipulation should begin at the outer or inner regions of a surfzone [23], where the water depth and the distance from the shore are not too high making the construction economically viable. However, the waves start breaking at the outer region and hence carry a significant proportion of the original wave energy. Even by the time the waves reach the inner region, they have dissipated only some of the energy although the wave shape begins to transform into a saw tooth shape. Wave breaking is not a requirement for this purpose although it is quite normal at low water depths. However, the optimum location for energy manipulation in the nearshore is still under research.

The construction of the wave manipulator would be analogous to the erection of a groyne with two additional sections, a funnel and a diffuser, which are oriented to the shore line at the optimum angle. Normally, a groyne extends into the surf zone where littoral drift is active, orienting the beach in line with the incident wave crests, hindering the alongshore current and facilitating the up drift sediment accretion [24]. In that context, the prototype wave manipulator would function as a groyne field, where the channel would identically function as a shore perpendicular groyne field with the rest of the sections functioning as an oblique groyne field.

Principally, groynes are useful in developing stable shore lines although they transfer the processes to down drift sites because up drift accretion implies down drift erosion. Therefore, in recent times hard coastal stabilization techniques have been used less frequently. Additionally, a groyne field would cause in the long run, a higher down-drift erosion compared to a single groyne. Hence, care must be taken in the functional design and the structural design [24] of a wave manipulator analogous to a groyne field by considering littoral processes as up drift protection will be guaranteed only at the expense of down drift erosion [25]. Moreover, a temporary erosion of the sea bed could be observed between the walls of the wave manipulator, which is linearly proportional to the spacing between the walls [25]. Hence, the width of the channel would be a crucial dimension as far as erosion is considered, and thus it has to be selected with utmost care. A width to length ratio of around 0.15 , as in the present study, would not cause severe erosion unless the channel is exposed to high tides, persistent oblique waves and unconsolidated sediments [26].

Therefore, it is required to select a bay site with a high probability of shore parallel wave crests minimizing alongshore sediment transport and updrift accretion caused by the presence of a wave manipulator. A bay with turbulent waves and multidirectional waves would change the shoreline stability in the long run which thereby affects the process of wave diffusion.

In constructing a wave manipulator, land based construction techniques could be used with the support of machinery such as crawler cranes and hydraulic excavators. Such land based techniques are viable in terms of safety and are more economical compared to ocean based construction techniques which have to use floating machinery. One of the major objectives of the present approach is to avoid such offshore construction techniques. Hence, the proposed structure could be sustainably constructed as a land based erection where the suitable rock armours could be dumped into the near coastal region starting from the swash zone.

Environmentally, the dumping of armours may create certain impacts on the surrounding marine ecology due to the fine dust that gets washed off from the large armours. In eco sensitive regions such as coral reefs, protected fish breeding areas and nursery grounds rich in certain species of protected vegetation (Posidoniasea grass, for example), dust plumes could cause an ecological imbalance, predation and extinction of species. These dust plumes usually persist for many days blocking out the sunlight and depositing fine dust on the gills of fish[27]. Hence, care must be taken in selecting a potential site for wave energy harnessing, without solely focusing on the wave 
environment in the site, but by giving equal attention to the ecological sensitivity of the region.

However, once the construction period is over, dust plumes will cease to exist. Conversely, a coastal structure such as a wave manipulator would be an ideal breeding ground for many species of fish. Furthermore, different marine flora and fauna which support aquatic life would grow on the structure and on the secluded sea bed outside the channel section.

Wave energy power plants do not produce greenhouse gases. However, some degree of environmental pollution can occur due to frequent personnel and boat movements, noise and oil spillages during the installation period [18].

A hard coastal structure in the nearshore may impair aesthetic amenities of certain communities. Therefore, the site selected for wave manipulation and power generation should not visually affect the inhabitants or adversely affect their commercial and recreational activities.

\section{Additional Benefits}

The enhanced sea waves inside the channel which have longer wavelengths and higher wave heights create offshore conditions, to a certain extent. Therefore, this manipulation would be suitable for some types of already available WECs. For example, a point absorber would find itself in high seas with much higher potential energy than when in coasts. A wave surge convertor would gain much more kinetic energy than in usual circumstances. An OWC too would benefit from the increased potential energy. An attenuator such as a Pelamis device could run along the channel acquiring considerable amount of energy. Therefore, wave manipulation generally produces offshore conditions nearshore for such WECs. In addition, the walls of the manipulator could guard them protecting them from storms and heavy winds. Note that a wave farm consisting of a large array of devices may require a substantially more area in the deep sea offshore [11] than what this approach does.

The structure of the wave manipulator is expected to span for some hundreds of meters into the surf zone. Therefore, the tops of the walls of the manipulator would be suitable for mounting wind turbines which will then form a combined wave and wind power station. In addition, this kind of a structure would be suitable for mooring ships and boats on the seaward side outside the channel, which is partly covered by the walls of the funnel and the diffuser. This secluded and calmer sea area would be ideal for the fishing industry allowing harboring small to medium boats.

\section{Conclusion}

A wave energy manipulator suitable for nearshore electricity generation was analyzed and tested. The parameters corresponding to the effectiveness of a model manipulator were found using wave flume tests in random wave states as well as in regular waves. The coefficient of energy density increase due to manipulation was found to agree with the predictions made, in approximating the funneling ratio in both kinds of waves. When the funneling ratio was set close to 2.7, the corresponding energy density increase was nearly 2.6 times. These results would be helpful in determining the optimum channel width and the funneling ratio. The energy density increase realized by wave manipulation was confirmed by tests done using axial flow, horizontal axis turbines. With a turbine blade wave capture area of only $27 \%$ during wave peaks, the conversion efficiency was as high as $43 \%$.

The process of wave manipulation would create offshore waves nearshore making it suitable for those WECs normally installed offshore. A structure built nearshore for wave manipulation would protect such WECs from offshore hazards simplifying maintenance problems and increasing their life time.

A wave manipulator would cause minimal changes to nearshore morphodynamics if the wave crests are mostly parallel to the shore. It supports the nearshore ecology creating ideal conditions for certain species of fish, other creatures and vegetation. Considering the extra benefits, a wave manipulating structure would function sustainably in the nearshore.

\section{Acknowledgment}

We acknowledge the support received from the staff working at the workshops of the Departments of Production Engineering and Electrical and Electronic Engineering and at the Fluid Mechanics Laboratory of the Faculty of Engineering, University of Peradeniya. We are also grateful to the final year project students of the Departments of Civil Engineering and Electrical and Electronic Engineering who were involved in this project. 


\section{References}

1. http://www.globalwavestatisticsonline.co m/Help/height_data.htm/,Visited, 2014.

2. http://www.oceanor.com/, Visited, 2014.

3. Barstow, S., Mørk, G., Lønseth, L. Mathisen, J. P., “WorldWaves Wave Energy Resource Assessments from the Deep Ocean to the Coast", Proc., 8th European Wave and TidalEnergy Conference, Uppsala, Sweden, 2009, pp. 149-159.

4. Mørk, G., Barstow, S., Kabuth, A., Pontes, M. T., "Assessing the Global Wave Energy Potential", Proc.,29th International Conf. on Ocean, Offshore Mechanics and Arctic Engineering (OMAE), Shanghai, China., 2010.

5. http://www.surf-forecast.com/, Visited, 2014.

6. Maliyadda, S. D. K., Wijeratne, W. M. C. R., Zoysa, S. R. L. M, Dias, D. D., JagathKumara, K. D. R., "Manipulation of NearShore Sea Waves for Electricity Generation: Modelling a Wave Concentrator", Proc., $5^{\text {th }}$ International Conference on Sustainable Built Environment, ICSBE 2014, Kandy, Sri Lanka, Vol. 3, 2014, pp. 206-216.

7. Jagath-Kumara, K. D. R., Dias, D., “Near Shore Wave Manipulation for Electricity Generation", WASET International J. of Energy and Power Engineering, Vol. 9, No. 7,2015, pp. 683-692.

8. Ross, D., Power from the Waves, Oxford University Press, 1995, pp. 156-168.

9. http://oceanlinx.com/, Visited, 2014.

10. Iglesias, G., Carballo, R., “Wave Energy and Near-Shore Hot Spots: The Case of the SE Bay of Biscay", J. Renewable Energy, Vol. 35, Issue 11, November, 2010, pp. 2490-2500.

11. http://hydropower.inl.gov/hydrokinetic wave/, Visited, 2014.

12. http://uekus.com/, Visited, 2014.

13. Morim, J., Cartwright, N., Etemad-Shahidi, A., Strauss, D., Hemer, M., "A Review of Wave Energy Estimates for Nearshore Shelf Waters of Australia", J. Marine Energy, Vol. 7, September, 2014, pp. 57-70.

14. Veigas, M., Ramos, V., Iglesias, G., “A Wave Farm for An Island: Detailed Effects on the Nearshorewave Climate", J. Energy, Vol. 69, May, 2014, pp. 801-812.
15. Khan, M. J., Bhuyan, G., Iqbal, M. T., Quaicoe, J. E., "Hydrokinetic Energy Conversion Systems and Assessment of Horizontal and Vertical Axis Turbines for River and Tidal Applications: A Technology Status Review", J. Applied Energy, Vol. 86, Issue 10, 2009, pp. 1823-1835.

16. Ortega-Achury, S. L., McAnally, W. H., Davis, T. E., Martin, J. L., Hydrokinetic Power Review, Civil and Environmental Engineering, James Worth Bagley College of Engineering, Mississippi State University, 2010.

17. http://www.emec.org.uk/marineenergy/wave-devices/,Visited, 2014.

18. Brooke, J., Wave Energy Conversion, Elsevier Ocean Engineering Book Series, 2003.

19. Furukawa, A., Watanabe, S., Okuma, K., "Research on Darrieus Type Hydraulic Turbine for Extra Low-Head Hydro Power Utilization", Proc., IOP Conference Series: Earth and Environmental Science, Vol. 15, Part 1, 2012.

20. Akylas, T. R., Mei, C. C., MIT Open Courseware - Modules on Waves in Fluids, Massachusetts Institute of Technology, 2001-2014, Ch. 6.

21. Chang, P., Melville, W. K., Miles, J. W., “On the Evolution of a Solitary Wave in a Gradually Varying Channel," J. Fluid Mechanics, Vol. 95, Part 3, 1979, pp. 401-414.

22. Robertson, J. M., Hydrodynamics in Theory and Application. Englewood Cliffs, NJ: Prentice-Hall, 1965, pp. 548-559.

23. Svendsen, Ib. A., Introduction to Nearshore Hydrodynamics. World Scientific Publishing Co. Pte. Ltd., 2006.

24. Coghlan, I. R., Carley, J. T., Cox, R. J., Davey, E. K., Blacka, M. J., Lofthouse, J., "Concept Designs for a Groyne Field on the Far North NSW Coast", Proc., NSW Coastal Conference, 12-15 November, 2013.

25. Mangor, K., Shoreline Management Guidelines, DHI Water and Environment, 2004, 294 p.

26. http://www.leovanrijn-sediment.com/, Visited, 2016.

27. Sciortino, J. A., Fishing Harbour Planning, Construction and Management, Food and Agriculture Organization of the United Nations, 2010. 